\title{
Urban Adolescents' Perceptions of their Neighborhood Physical Activity Environments
}

\section{CORRESPONDING AUTHOR:}

Sandy Slater, $\mathrm{PhD}$

Institute for Health Policy Research

University of Illinois at Chicago

1747 W. Roosevelt Rd., Room 558

Chicago, IL 60608

Email: sslater@uic.edu

Phone: 312-413-0475

Fax: 312-355-2801

CO-AUTHORS:

Marian Fitzgibbon, $\mathrm{PhD}$

Department of Medicine and School of Public Health

University of Illinois at Chicago

Myron F.Floyd, $\mathrm{PhD}$

Department of Parks, Recreation and Tourism Management

North Carolina State University

Key Words: adolescents, obesity and overweight, physical activity, parks, marginalized populations 


\begin{abstract}
Reduced physical activity is particularly pronounced among lower income individuals and racial/ethnic minorities, and may be related to unsupportive neighborhood environments for physical activity. The purpose of this research was to conduct focus groups with low-income urban Black and Latino adolescents to identify whether these adolescents were physically active, in what settings, and what features of the settings were important for encouraging their physical activity. Results suggest potential gender differences, but little difference across race/ethnicity. Results can inform the development of a park/physical activity setting characteristics survey to help improve conditions of parks.
\end{abstract}




\section{Introduction}

Recent evidence by Ogden, Carroll, Kit, \& Flegal (2012) shows that nearly one-third of U.S. youth are overweight or obese. During the past few decades the rates of obesity have tripled for adolescents. Even more alarming is that 21.2 percent of Latino and 24.3 percent of Black children and adolescents are obese in comparison to 14 percent of white youth (Ogden et al., 2012). Furthermore, Miech, Kumanyika, and Stettler (2006) found the prevalence of obesity to be significantly higher by a difference of 11 percent among low- versus high-income groups.

Increasing physical activity is one way to address the growing problem of these disproportionate racial, ethnic and socioeconomic differences in childhood obesity (USDHHS, 2008). Yet differences in physical activity levels also exist across age, gender, race/ethnicity, and socioeconomic status. Recent evidence shows that 6 to 11 year old children engage in twice as much physical activity as 12 to15 year olds, with 12 to 15 year old Latinos being the least active in comparison to white and black adolescents; this decline in physical activity continues into adulthood (Belcher et al., 2010). Males are more active than females, with Black females being the least active across race/ethnicity (Belcher et al., 2010). Finally, lower-income youth participate less in physical activity (Crespo, Ainsworth, Keteyian, Health, \& Smit, 1999). These findings stress the need to improve the physical activity behavior of adolescents so that they may carry these healthier habits into adulthood. One solution is to encourage greater use of local parks. Public parks are generally free and can provide a convenient and safe recreational space for low-income youth who may not have resources available to them to travel to recreational facilities, or pay for sports programs or membership fees. Public parks could also be a particularly important physical activity resource to lower-income urban youth who may not have yards or other home-based play areas available to them. However, adolescents are the least likely 
group to use parks (Shores \& West, 2008; Cohen et al., 2007). Given the identified physical activity differences and the greater risk of obesity in these sub-groups, it is important to recognize what physical activity settings, activities, and programs are not only important for these subgroups, but also available and accessible to them.

To date most research studies have examined proximity and density of PA settings and their effect on physical activity behavior in adolescents (Brodersen, Steptoe, Williamson, \&Wardle, 2005; Cohen et al., 2006; Gomez, Johnson, Selva, \& Sallis, 2004; Gordon-Larsen, McMurray, \& Popkin, 2000; Mota, Almeida, Santos, \& Ribeiro, 2005; Norman et al., 2006; Powell, Chaloupka, Slater, Johnston, \& O’Malley, 2007a; Sallis, Nader, Broyles, \& Berry, 1993; Timperio, Crawford, Telford, \& Salmon, 2004), very few studies have examined what types, features or other park characteristics encourages adolescents to utilize parks (Brownson, Hoehner, Day, Forsyth, \& Sallis, 2009). Perceived environmental barriers, such as lack of access, have also been associated with lower-income neighborhoods (Moore, Glick, Romanowski, \& Quinley, 1996; Powell, Slater, Chaloupka, \& Harper, 2007b) and lower levels of PA in adolescents (Babey, Hastert, Yu, \& Brown, 2008). Physical activity settings in low-income neighborhoods have also been shown to have lower quality features in existing facilities (Humbert et al., 2006), and less affluent communities may not offer the same types or variety of physical activity opportunities (Gordon-Larsen, Nelson, Page, \& Popkin, 2006; Powell, Slater, \& Chaloupka, 2004; Powell, Slater, Chaloupka, \& Harper, 2006). Evidence shows that low-income and minority neighborhoods have fewer opportunities for Park and Recreation Departmentsponsored programs, with Latino and Asian neighborhoods experiencing fewer opportunities than Black neighborhoods (Dahmann, Wolch, Joassart-Marcelli, Reynolds, \& Jerrett, 2010). 
According to Broderson et al. (2005), the gold standard method for collecting information on physical activity settings has typically been on-site observations of physical activity venues using, sometimes lengthy audit instruments. This can be costly and time intensive, restricting sample sizes for research studies, and limiting its application to advocacy organizations and others interested in measuring these settings. Two recent literature reviews revealed a lack of validated self-report measures related to parks and trails (Broderson et al., 2005; ALR, 2010) and others highlight the need for future instruments to be developed to address the needs and conditions of low-income minority communities (Floyd, Taylor, \& Whitt-Glover, 2009; Kumanyika \& Grier, 2006). There is also a growing body of evidence stressing the need to include youth in the development and implementation of interventions (Naylor \& McKay, 2009). Thus, there is a need to test the feasibility of gathering this information from special populations, such as low-income minority youth, who are most in need of health behavior change efforts.

Recent research using direct forms of observing parents and children and objective measures of park attributes found that park quality is an important determinant of park use by children (Loukaitou-Sideris, 2002; Tucker, Gilliland, \& Irwin, 2007). Low-income youth have also reported that nearby recreation facilities are more important for their physical activity than more affluent youth (Humbert et al., 2006), most likely because they have limited access to more expensive or distant locations. However low-income and minority populations most at risk for physical inactivity and obesity have access to fewer available outdoor physical activity-related settings (Powell et al., 2006). Tester and Baker (2009) examined visitation and physical activity levels in two California parks located in low-income neighborhoods that underwent sports field improvements, and found a 4-fold increase in visitation by both children and adults after improvements were made, suggesting that the condition, as well as presence, of physical activity 
settings is important to increase the use of facilities. Therefore, the purpose of this study was to conduct focus groups with Black and Latino adolescents to determine what park characteristics influence utilization of parks by adolescents in an effort to identify ways to provide more opportunities for physical activity in this at-risk population. The study sought to identify where adolescents were physically active and what features of these settings were important for encouraging their physical activity. Identifying these physical activity settings and their specific characteristics can help inform local governments and their park and recreation departments about which physical activity features are important investments for increasing physical activity levels in these vulnerable populations or help identify areas to target for future interventions.

This research follows an overarching socio-ecological framework which postulates that changes in individual characteristics are affected not only by personal factors (e.g., age, gender, SES, race/ethnicity, genetic profile) but also by interactions with the larger social, cultural, and environmental contexts in which they live (e.g., family, school, community) (Davison \& Birch, 2001; IOM, 2005; Sallis et al., 2006). Our conceptual model derives from this framework, focusing on the specific environmental factors affecting the overall park environment. Parks and their associated community recreation facilities provide opportunities for physical activity and active living, which in turn can help mitigate related health problems that disproportionately impact low income minority neighborhoods. This study also accounted for environmental justice principles and deprivation amplification as they relate to the quality and level of maintenance of public parks and their associated facilities, such as community recreation centers or Boys and Girls Clubs of America located in low-income minority communities (Floyd et al., 2009; Taylor, Floyd, Whitt-Glover, \& Brooks, 2007). For example, poorly maintained parks and recreation facilities are magnets for criminal activity and discourage use by community residents whose 
perceptions of social disorder are related to perceived fear of crime (Lane\& Meeker, 2003; Lane $\&$ Meeker, 2005) .

\section{Methods}

In April 2010 Black and Latino and Latina $6^{\text {th }}, 7^{\text {th }}$ and $8^{\text {th }}$ grade adolescents were recruited to participate in a series of focus groups. The primary purpose of the focus groups was to determine why youth utilize or avoid specific physical activity locations. Focus groups allowed research staff to draw upon the adolescent participants' attitudes, feelings, beliefs, experiences and reactions related to their neighborhood physical activity-related supports and their own physical activity behavior. Focus groups take advantage of the fact that people naturally interact and are influenced by others, thereby providing high face validity for the information obtained through the groups (Krueger \& Casey, 2000).

Participants were recruited by the lead author and the grant project manager from two purposively selected public schools located in a large city based on the racial/ethnic and socioeconomic characteristics of the student body. Participant, school and neighborhood characteristics are shown in Tables 1 and 2. School A's student body is 99.2 percent Black and 99.8 percent of its students receive reduced/free meals. There are 14 PA settings (four parks, two schools, and a mix of eight nonprofit and for-profit indoor facilities) within walking distance to where the students live or go to school. School B's student body is 95.7 percent Latino and 94.7 percent of its students receive reduced/free meals. There are seven PA settings (two parks, two schools and three indoor facilities) within walking distance to where the students live. All information on neighborhood PA settings was identified by study staff using a combination of 
local maps, local directories, and business list data. Both schools are neighborhood schools with the majority of students living close enough to walk to school.

$<$ Tables 1 and 2 about here>

A letter was sent home to the parents/legal guardians of all $6^{\text {th }}, 7^{\text {th }}$ and $8^{\text {th }}$ grade students at both schools $(\mathrm{N}=450)$. The letter notified parents that study staff would give brief presentations to explain the research study and invite the adolescents to participate in the focus groups. Consent and assent forms were then sent home with interested students $(\mathrm{N}=100)$. After study staff gave the brief presentations, flyers advertising the focus group recruitment efforts were also posted at the schools. The flyers provided tear off sheets with contact information for study personnel as a means to further promote the study and increase participation in the focus groups. A total of 42 signed student assent and parental/guardian consent forms were returned. Reminder letters regarding the location, date and time of the focus groups were mailed to all students who provided the necessary consent documents. Four focus groups (one all-male and one all-female group per school) were held after school in May 2010 with 6-10 participants per group. Students were paid $\$ 20.00$ for their participation. Economic incentives were provided, because they have proven to increase study participation in under-served and vulnerable populations (Singer \& Kulka, 2002). The use of incentives is based on the idea of "giving something to" participants, rather than "taking something from" them. Thirty-three of the 42 registered students showed up on the scheduled day of their respective focus group. A total of 19 females and 14 males participated. The focus groups lasted about one-hour and were conducted at school after students were finished with classes. Focus groups were conducted by trained 
moderators matched to the groups by race/ethnicity with backgrounds in community-based participatory research and strong relationships in both communities.

The moderators followed a structured discussion guide containing key topics of interest with follow-up probes. Focus groups were audio-taped using digital recording devices and two staff members (the lead author and the project manager) took detailed notes. Focus group recordings were transcribed by study staff within one-week of the completion of the focus group. The discussion guide questions focused on the types physical activity the youth engaged in; who they exercised with; where they went to be physically active; why they chose certain physical activity locations over others; what types of features are present at the locations they visit; how the locations look and the condition of the present features; how easy it is to use the locations; when they use the locations; and, how they like to identify the locations (either by park/physical activity setting name, nickname (e.g., "Locust Park" because it is located on Locust St.), or photo). The lead author, who served as the assistant moderator, was present at all focus groups and had the opportunity throughout the groups to ask follow up questions in order to clarify or expand upon participant responses. The moderator and assistant moderator conducted member checks, by restating or summarizing the information provided by participants, throughout the focus groups to determine and ensure accuracy of participant responses. The moderator also asked an ending question at the close of the focus groups to determine and validate the final positions of the participants (Morgan and Krueger, 1998).

\section{Data Analysis}

Using focus group analysis techniques, outlined in Morgan and Krueger (1998), data analysis was an ongoing process that started by listening during the groups and continued 
throughout the study. The lead author used transcript-based techniques to analyze the data (Morgan \& Krueger, 1998). The transcript-based technique for this paper used a combination of transcription documents, field notes, and debriefing discussions to conduct, by hand, a questionby-question analysis. This method of analysis was selected because it has a high level of rigor and a low risk of error (Krueger \& Casey, 2000). Questions and/or questions that grouped into topic areas were identified. Comments to these questions/topic areas were then recorded under each question/topic area (e.g., types of physical activity locations, barriers to physical activity, safety issues) heading. All responses to the same questions from all focus groups were read and a summary description of the responses was written. Focus group transcripts were reviewed, read line-by-line, and coded separately to determine common themes and trends. Words or sentences that captured the critical issues/thoughts of the participants were highlighted to help identify patterns/themes in the data. Summations of question responses/topic areas were then developed and reviewed for accuracy by the project manager who was also present at all focus groups.

The research team employed multiple strategies to validate data and ensure the trustworthiness of the results. First, data were gathered from focus groups conducted across gender, race/ethnicity, and different neighborhoods (Curtain \& Fossey, 2007). Second, data were analyzed using multiple sources (transcripts, field notes and debriefing). Third, results of the data analyses were discussed and agreed upon with focus group moderators, who were not involved in analyzing the data. Finally, as previously mentioned, member checks with focus group participants were conducted throughout the focus groups themselves, but were not conducted after the data were analyzed. This is a potential limitation of the study. However, because the research team employed multiple validation strategies for this study, including reaching consensus of interpretation of results among the lead author, project manager, and focus group 
moderators in conjunction with member checking during the focus groups, should significantly reduce the risk of presenting untrustworthy results.

\section{Findings}

Although the two neighborhoods and schools where focus group participants were recruited had different demographic characteristics (e.g., School B had double school population size and almost double land size of School A, and both schools/neighborhoods had different predominant racial/ethnic groups), no clear differences were found in participant responses across school/neighborhood responses. Some differences were found in responses across gender; with adolescent males and females across schools/neighborhoods having similar responses (see Table 3).

<Table 3 about here>

\section{Youth Physical Activities and Locations}

Youth were asked what they do for physical activity. Almost two-thirds $(\mathrm{N}=22)$ of the adolescents stated they were involved in organized sports programs either offered through their school, a local non-profit after school program, or through the park district. They stated these activities were their primary sources of weekly physical activity outside of school, and that these programs were held at their school, local parks or through local non-profit after school programs. Latina participants also talked about being physically active — running around and playing — in their backyards. However, the majority of adolescents did not mention being physically active at home. 
Males in both groups talked about participating in competitive sports leagues $(\mathrm{N}=11)$, whereas females in both groups participated in more informal activities, such as, intramural sports leagues $(\mathrm{N}=6)$, jumping rope or playing tag with friends, and participating in organized playground activities, such as rotating through designated physical activity stations, designed by after school program staff. This was particularly true for the Black girls; with half $(\mathrm{N}=5)$ participating in physical activity activities provided through a local after school program and the other half $(\mathrm{N}=5)$ not being involved in any organized physical activities. "When we're at the parks, we're running around, like cause we be playing with the boys [sic.]; we play basketball and monkey ball, sitting and talking, and sometimes I play on the swings" (Black Female). Adolescents across all groups participated in programs offered in their neighborhood, and with one exception, did not generally leave their neighborhood to participate in these programs. There was one Latino who played competitive soccer and mentioned that his mother drove him to different locations for games, including some suburban locations.

All participants talked about visiting two to three settings regularly (defined as once a week or more). Focus group participants were asked to specifically name the physical activity settings they frequent, and these settings were predominantly the same across the groups within the schools. The types of primary locations mentioned included: local parks including park field houses/gyms, local high school fields and gyms, as well as their own school, and a local nonprofit organization's facility which runs an after school program. The primary reason youth gave for visiting one location over others was convenience. "Because I live near it, because that's where you always, like always been, and you would always play there, because you live near it, and you don't have to travel that far, that you have trouble getting back to your house [sic]" (Black Male). "I go to the park that's close to my house and because my friends go there" 
(Latina). There was a YMCA located in the predominantly Black neighborhood, but none of the participants were members and participants reported the local Boys and Girls club recently closed. Similar results were found in the predominantly Latino neighborhood with two exceptions, two Latino males attended instructional schools (e.g., a privately run Martial Arts facility). When asked if they attended an after school program, YMCA or Boys and Girls club, all the Latino females either shook their heads to indicate "no", or said nothing.

Male participants, in both groups, when asked about whom they exercised with, talked primarily about participating on a sports team or going to a park or their school and playing with either their friends or other kids visiting these locations. Female participants in both groups had similar responses, but also mentioned playing with relatives. They did not play with other kids visiting the parks/schools. The females at both schools mentioned that seeing your friends at the park was one of the main reasons they visited a certain park. "I play on the playground or just walk around with friends" (Latina). "I like to swing on the swings and walk around with my friends" (Black Female). The females talked much more about who they were with when visiting a park and the males talked about what types of activities they participated in at a park as the main motivator for visiting a certain park.

All participants were asked about how often they visit physical activity-related locations. The males stated they visit parks and other physical activity settings daily. The females' responses ranged from three times a week to every day. Participants' primary reason for visiting certain locations was to participate in local sports programs. Male participant's secondary reason for visiting parks was to play pick-up games of soccer, basketball, etc. with other males and females' secondary reason was to hang out with their friends. 


\section{Park/PA Setting Utilization of Features}

Adolescents were asked what types of features they utilized when visiting the local parks/physical activity settings. Both males and females at both schools regularly utilized sports fields and courts through their organized sports programs. Males also utilized indoor gymnasiums that offered open gym hours. The females did not utilize the open gyms. The females used the playground equipment, in particular swings, while hanging out with friends at the parks. Both females and males utilized local outdoor pools.

\section{Types and Condition of Park/Physical Activity setting Features}

Youth were asked what types of features, regardless of whether they use them or not, are available at the parks/physical activity settings they visit frequently and about the condition/quality of park/PA setting features. All four focus groups were asked identical questions and probes, yet there were gender differences in the youths' knowledge about the presence and condition of features. Female participants at both schools had a hard time identifying all the features present at parks/physical activity settings and their responses tended to focus more on generalities. However, they were aware of the poor condition of park features. "They need to be improved. They're big...I'd like more stuff to play with, more equipment, like, like, um.... [sic]” (Black Female). "The park doesn't have a lot of sports things and there's garbage and spray paint everywhere" (Latina).

The males were much more knowledgeable about the presence and condition of features, as well as programs offered at the parks/physical activity settings. They could easily recall the different types of courts and fields available both indoors and outside, as well as whether there were drinking fountains, shelters, and bathroom facilities. When asked about a park field house, 
one youth stated: “Inside there's um boxing, and I've played basketball. They got exercise classes up there and they've got dance too...like hip hop and stuff, and they got poetry, and a gym downstairs and a pool in the back" (Black Male). When asked about the condition of outdoor fields and courts male youth stated:

"The fields are like unsafe. When you play soccer and you trying to dribble the ball, like the ball falls because it's uneven grass. There's only one good field for soccer. The rest, they have big ol' holes in the ground" (Latino).

"The basketball hoop, the basketball court on one side is lopsided. You put the ball down and it will roll to one side. I remember this one game they had to change it, they had to postpone it because they had glass all over the courts" (Latino).

The males at both schools could easily describe the condition of features they utilized, but were also familiar with the condition of features they used infrequently. They were also knowledgeable about which facilities offered free sports programs, such as open gyms, what days and times they were offered, as well as the general operating hours of the facilities/parks they visited including age-restricted areas, such as exercise rooms. They were also familiar with fee-based programs, but were less knowledgeable about the specific cost of the program. There were certain features that were unimportant to the adolescents. For example, when facilitators asked if the parks had adequate lighting that would allow youth to exercise at night the youth responded by saying the gangs use the parks at night thus hanging out in parks after dark is not an option. "It's safe to be out in the morning time. It's safe between like 1 to 5, but 
like at 6 uh uh, oh no, it's not safe cause there's shootin' [sic.]. Well sometimes it do be safe because you can't stay in the park that long, the police arrive and say you gotta go [sic.]" (Black male).

Both males and females were knowledgeable about the cost of programs or fees associated with specific physical activity settings. However, males in both groups were also knowledgeable about operating hours (e.g., when they close, what times they offer open gym) at the facilities, as well as age restrictions for certain features, such as the exercise room at a local field house. "Dance classes you have to pay[sic.], the pool is free, open gym is free and is open from 3 to 8:30 pm Monday through Saturday, but you can't be there unless there's an adult" (Black Male). "There's a gym at the park, but you have to rent it. The soccer league costs like $\$ 100 ”($ Latino).

\section{Alternative Locations}

Although participants discussed visiting local parks/PA settings regularly, they also exercised at other settings. The most often mentioned alternative locations visited by focus group participants $(\mathrm{N}=20)$, aside from local parks, were school playgrounds and fields after school hours. All groups mentioned playing at their own school, but also playing at nearby high schools that offered more features, such as sports fields. The males in both groups discussed utilizing other neighborhood locations for pickup games of basketball football or soccer. These alternative locations included a church parking lot and vacant neighborhood lots. Generally the males do not play in the streets or alleys near their homes. They talked about being creative in how they take advantage of vacant lots. For example, some of the adolescents were involved in constructing a 
dirt bike track on some open land in their neighborhood. "There's this dirt thing, and we go behind, this man helped make it for us, so we can ride our bikes on it" (Black Male).

Alternatively the females in both groups consistently said that they do not exercise or hang out in alleys, streets, vacant lots, or any other neighborhood setting. Both female groups said they will walk around their neighborhoods with a group of friends. Also, Latina participants mentioned spending a lot of time at their friends' houses and the Black females mentioned frequently visiting the local mall as a place to walk around.

\section{Barriers to Physical Activity}

The females in both groups mentioned homework and household chores as barriers to being physically active. However, they felt that they were just as active during the week as they were on weekends. They all agreed that they are more active during the summer than during the school year because school responsibilities leave very little time for exercise. "I'm more active during the summer because you have the whole day to go out and when we're in school we only have a little bit. You have more time to walk around stores, or go to the store, you swim more, ride bikes” (Latina). “When its cold you can't do anything cause like...you get tired...come home [sic.]" (Latina).

Results of the male focus groups varied slightly. Black males stated that very little kept them from being physically active. "I play basketball in the rain, uh huh, and football in the snow. Its better when it's warm, but I still do it in the wintertime" (Black Male). "When it's cold and I'm with my cousin we always go outside in the snow. As soon as it hit dawn we clean up, eat breakfast and go. In summer we go to a big pool for five or six hours and then we get out at night we would play, fight in the grass, and we go eat, wash up" (Latino). Similar to the females, 
Latino males cited homework and family obligations as a barrier to being more physically active. "Taking care of my cousins keeps me from going to the park and homework too" (Latino). They stated that they were able to be more physically active on weekends versus weekdays during the school year because some days it's too late to go to a park or other physical activity setting due to time-consuming homework. "You get to do more fun stuff and can stay out more. On the weekend I gotta [sic.] come in like at 10 or 11 or later cause my mother and Dad be in front of the house doing grown up things and they be stayin up to like five or six in the morning" (Black Male). Consistent with the females across both groups, both Black and Latino males said they exercise more in the summer because they have more free time. However, all groups said there is a greater gang presence in the parks during the summer months.

Overall, both male and female groups complained that although they have more time to be physically active during the summer, their neighborhoods lack a sufficient number of PA programs during the summer months. "Like if they offered more programs at the parks, it would bring in more people who wouldn't be doing bad things" (Latina). The Latino participants also cited this as a problem during the winter as well. Lack of programs did not appear to be a problem with the Black participants.

\section{Park/Physical Activity Setting Safety Issues}

Focus group facilitators asked about supervision in the parks/physical activity settings and other safety issues being barriers to physical activity. This probing generated a lot of discussion amongst the participants. Participants were in agreement that most of the parks/physical activity settings and many of the local park programs lacked proper supervision. "They have [sic.] park program teachers there like, what do you call them....or whatever, my 
mother went there and signed my brother and sister up there one time and then there was gymnastics and wrestling and some other stuff and we just seen a bunch of kids just running around playing; there was no adult or nothing man and there was just one just one adult sitting at the little center thing and doing nothing” (Latino). Both males and females stated there was not enough adult supervision at the parks by either park personnel or parents and that supervision is important to them when making the decision to visit one park/setting over another. The females also felt it was important to visit parks where they knew a lot of people because this made them feel safer.

"When there's people at the parks and fields, you feel safe surrounded by people that you know and can call for help. Most of the times it's like kids or adults or family members that are out there with you so you can feel safe and secure like, but it isn't you by yourself or you and your friend. Your friend can get hurt too. You have to have a surrounding of people. They say it's better in numbers" (Black female).

"There's bad people around the park, but I'll go there if I go with a big group of friends and there are other kids there that I know" (Latina).

The lack of supervision appears to facilitate increased gang activity in the neighborhood parks. However, adolescents have developed strategies to handle this. Gang presence is prevalent at all local parks visited by the participants. However, the participants talked about ways they navigate the parks to avoid confrontation with gang members. Gang activity at the larger parks appears to be concentrated in certain areas, while leaving other sections of the park available to 
the youth for exercise or hanging out with friends. On the other hand, gang activity in smaller neighborhood parks made it virtually impossible to utilize those settings without risking confrontation. " A lot of people were scared of going to [sic.] park, like there's a lot of gangs and a lot of bad people. That whole area, if you're wearing the wrong color and you are just trying to match, they'll try to start something with you, and you're just there to exercise" (Latino).

The focus group participants cited their parents as barriers to visiting certain parks due to their concern about the high prevalence of gang activity and violence in the parks. Participants in all four groups were aware of recent gang-related killings that occurred in their local parks. "My friend called my cell phone and he say him [sic.] and some of his friends from this school are going up to the park and he told me to ask my mother if I could come and that his mother would pick me up and when I told my mother she like "Mm, no, who's gonna be there?" and I told her his mother would be there and she said she don't know because it was only like, a couple weeks after a shooting. She was worried" (Black male). However, some participants ignored their parents concerns. For example, one Latino male stated, "Your parents see you coming from that park and they say where you just come from [sic.]? I told you not to go over there, there was a shooting there yesterday, now why don't you see what happens?"

Specific to both the male and female Latino focus groups, parents appeared to encourage their children to utilize alternative neighborhood settings. "Parents think it's safer to play in the alleys. A lot of shootings happen in the park. They (parents) want you to be close to the houses. My parents know that it is safe because nothing happens on my block. They probably just feel more comfortable with it" (Latino). 
When asked how they determine if a place is safe, participants mentioned they know it is safe if there is no garbage or spray painting and the setting is surrounded by nice houses. They also talked about safe parks as having features that were in good condition. The Latino males spoke about a specific park as being divided into a good half and a bad half. "One side is clean and the other side is messed up. They got a basketball court on both sides, on one side the nets are all messed up and the hoops all crooked. On the other side the net might be a little messed up, but it's better than the other side. One side's got a play ground for kids and the other one doesn't" (Latino). When asked what makes a difference between the two sides of the park, the Latino male said the following: "There's a busy street on one side, but it has a lot of houses. The other side is a lot of buildings and one is a liquor store. People be [sic.] over there in the dark posted up on the corner and stuff" (Latino).

Although all participants stressed safety of the parks/physical activity settings as a concern, both in terms of exposure to violence and poor condition of the facilities, these issues did not prevent the participants from using many of these facilities, given that, for the majority of participants, they are the only facilities accessible to them. There were certain locations participants completely avoided. One example was a park they called "Bogus Park".

“At Bogus Park, there's a lot of gangs, that whole area if you're wearing a color and you are just trying to match, they'll try to start with you, and you're just there to exercise [sic]. Somewhere where you got shade, when you out in the summer, when you out playing you get extra hot, and you just want to sit down and cool off cause you're hot, hot, hot, and you want to sit up under a tree and get cool like, ah, I'm just going to fall asleep out here. Fall asleep up there and you'll get robbed. Wake up, pants gone, shoes gone” (Latino). However, they clearly 
would like to see the condition of the facilities improved, more programs targeted to their age group offered, and solutions provided for the gang and other violence that is prevalent in the neighborhoods.

\section{Discussion}

The purpose of this research was to determine where low-income urban Black and Latino adolescents were physically active and what features of these settings were important for encouraging their physical activity. Focus group findings suggest that these adolescents primarily visit neighborhood locations that are conveniently located to their homes regardless of the quality or types of features available. Only one youth participated in activities outside their neighborhood. This finding is inconsistent with existing evidence that showed the importance of facility quality on physical activity behavior (Ries et al., 2008). It is possible most of the participants did not have the resources available, such as money to pay for more expensive programs or transportation to facilities outside their neighborhoods, to participate in better organized programs or visit better maintained settings. Therefore, the participants utilized those settings to which they have access and where the sports programs they were involved in were held.

Similar to Grow et al. (2008), adolescents stated they regularly visit approximately 3 settings and the most frequently used sites were fields/courts, indoor recreation facilities, small and large parks, and swimming pools. Some gender differences were found in the preference and use of certain park features. Adolescents in the study were familiar with the barriers/issues that make it more challenging to visit these settings. Consistent with previous research (Cohen et al., 2006; Humbert et al., 2006; Ries et al., 2008), the presence of adult authority figures such as 
parents, park staff or police officers, was important to the youth, but inconsistent with these same studies (Cohen et al., 2006; Humbert et al., 2006; Ries et al., 2008) the lack of adult supervision did not prevent participants from frequenting these settings.

In general the female participants were more concerned than male participants with how "people friendly" the settings were. In other words, they were more concerned with how safe the locations were rather than their physical condition. Perceptions of neighborhood safety have previously been associated with decreased physical activity in females (Sallis et al., 1993; Slater et al., 2010). Given that females of any race/ethnicity spend less time being physically active than males (Belcher et al., 2010), and the importance of perceived neighborhood safety on physical activity, it is important for future physical activity research to target interventions designed to address safety issues. In contrast, males were very vocal about the physical condition of the physical activity settings. They also were concerned with safety issues, but not to the same extent of the females. It was apparent across both genders that these youth were very aware of the safety issues in their neighborhoods, as well as being very knowledgeable about how to best navigate these environments to avoid unwanted confrontations. This may be best highlighted by the youths' perceptions about the importance of park lighting, which was not at all important given the fact that local gangs frequent the parks in the evenings, thus making parks unsafe places to be after it gets dark regardless of lighting. This finding is consistent with research conducted by Stodolska, Acevedo, and Shinew (2009) where they found that park users employ avoidance and protective behaviors, such as choosing particular times and locations to avoid gang activity, as well as visiting parks with groups of friends.

Studies by Moore et al. (1996) and Powell et al. (2007) have shown environmental barriers, such as lack of access to physical activity settings, have also been associated with lower 
income neighborhoods. These focus group results were mixed. The Black participants did not perceive a shortage of opportunities in their neighborhood, but the Latino participants did. Given that these previous studies suggested the need for increasing the availability of PA settings in minority neighborhoods, it is important to collect information on both proximity to, as well as the overall condition of available physical activity settings. The Latino neighborhood had half the number of physical activity settings as those identified in the Black neighborhood and twice as many students attending School B. This may help explain why the Latino participants utilized alternative settings for physical activity more regularly than any of the other participants. The Latinas, on the other hand, did not utilize alternative settings. Rather, they mentioned spending more time at their or a friend's home because there were fewer opportunities available to them. This resistance by females to utilize alternative settings for physical activity may also help explain why females generally have lower physical activity rates than males (Belcher et al., 2010).

The males in both groups discussed participating frequently in free or low-cost neighborhood physical activity programs (e.g. open gym). Males were proactive about identifying the free/reduced cost after school physical activity opportunities available in their neighborhoods and actively utilized these programs, whereas females did not mention these programs, nor did they utilize them. However, most of the Black females were involved in an after school program offered through a local nonprofit organization. They participated in organized physical activities through this program. The Latinas did not have a similar program available to them. Again this suggests differential access to physical activity or other after school opportunities by neighborhood. 
One clearly important physical activity setting for these youth was their own schools, as well as other local schools in their neighborhoods, in particular the local high schools. All participants mentioned spending time utilizing school play grounds after school hours or visiting the local high school to play on the sports fields. This helps support the case for open campuses or more formal joint use agreements with local park and recreation departments.

Contrary to previous research (Floyd, Spengler, Maddock, Gobster, \& Suau, 2008) showing differences in how Blacks and Latinos utilize park features, we generally found few racial and ethnic differences in park utilization by adolescents. Physical activities utilized by adolescents aged 11 to 14 years old are still very structured, with most of the participating youth being involved in some type of organized sports program either through their school or a local neighborhood organization. However, gender differences were identified in park utilization and differences in the availability of physical activity settings by neighborhood.

Finally, consistent with research conducted by Miles (2008), signs of physical disorder (e.g., graffiti, litter, broken glass) were associated with perceived neighborhood safety, and safety also influenced parents' decisions to allow their children to frequent local parks. In neighborhoods with limited physical activity settings this severely reduces the choices youth might have available to them to be physically active. These results indicate a need for better facility maintenance of physical activity settings particularly in low-income neighborhoods. They also indicated that it is important to not only examine the number of available physical activity settings in a neighborhood, but to also develop methods to determine the quality of those settings and how this is associated with physical activity.

\section{Conclusion}


Similar to previous studies, we found that the lack of adult supervision (Cohen et al., 2007; Humbert et al., 2006; Ries et al., 2008), availability of PA settings and programs (Humbert et al., 2006; Ries et al., 2008), and safety issues Humbert et al., 2006; Ries et al., 2008; Slater et al., 2010) all play a role in influencing adolescent utilization of parks. Results of these focus groups highlight some important research implications for further study. Future research should: a) identify which features may be important for encouraging physical activity in both male and female adolescents, particularly those living in under-served communities; b) evaluate joint use as a policy intervention to increase physical activity in park/physical activity facilities; c) identify and evaluate available park programs across communities to help guide municipalities in how to improve their program offerings; and, d) link parks/physical activity facilities to urban form and street connectivity to better understand street-level and pedestrian network conditions, which could be an avenue for extending the range or geography of the youth.

The results of these focus groups may be used to help address some of these issues by informing the development of a self-report survey of park/physical activity setting characteristics to help identify what features are most important for encouraging physical activity in lowincome urban Black and Latino adolescents, as well as how to improve those features in their neighborhoods. The development of a self report survey will not only help to identify the condition of parks/physical activity settings, but it can also be used to identify availability of these locations, as well as which features are more likely to increase physical activity behavior. The findings from this survey could help inform policy and environmental change to support physical activity and could then be used to provide local park department officials with information on where to focus their resources. 


\section{Acknowledgments}

Funding for this research was provided by The Robert Wood Johnson Foundation (RWJF)

Active Living Research Program. Views expressed are those of the authors and do not necessarily reflect the views of RWJF or the University of Illinois at Chicago. 


\section{References}

Active Living Research (ALR), Research Synthesis (2010). Parks, playgrounds and active living (2010). http://www.activelivingresearch.org/files/Synthesis Mowen Feb2010.pdf

Babey, S.H., Hastert, T.A., Yu, H., \& Brown E.R. (2008). Physical activity among adolescents: When do parks matter? American Journal of Preventive Medicine, 34, 345-348.

Belcher, B.R., Berrigan, D., Dodd, K.W., Emken, B.A., Chou, C., \& Spuijt-Metz, D. (2010). Physical activity in US youth: Impact of race/ethnicity, age, gender and weight status. Medicine and Science in Sports and Exercise, 42(12), 2211-2221.

Brodersen, N.H., Steptoe, A., Williamson, S., \& Wardle, J. (2005). Sociodemographic, developmental, environmental, and psychological correlates of physical activity and sedentary behavior at age 11 to 12. Annals of Behavioral Medicine, 29(1), 2-11.

Brownson, R.C., Hoehner, C.M., Day, K., Forsyth, A., \& Sallis, J.F. (2009). Measuring the built environment for physical activity: State of the science. American Journal of Preventive Medicine, 36(4S), S99-S123.

Cohen, D.A., Ashwood, J.S., Scott, M.M., Overton, A., Evenson, K.R., Staten, L.K. et al. (2006). Public parks and physical activity among adolescent girls. Pediatrics, 118(5), :e1381-e1389. 
Cohen, D.A., McKenzie, T.L., Sehgal, A., Williamson, S., Golinelli, D., \& Lurie, N. (2007). Contribution of public parks to physical activity. American Journal of Public Health; 97(3): 509514.

Crespo, C. J., Ainsworth, B. E., Keteyian, S. J., Heath, G.W., \&Smit, E. (1999). Prevalence of physical inactivity and its relation to social class in U.S. adults: Results from the Third National Health and Nutrition Examination Survey, 1988-1994. Medicine and Science in Sports and Exercise; 21, 1821-1827.

Curtin, M., \& Fossey, E. (2007). Appraising the trustworthiness of qualitative studies: Guidelines for occupational therapists. Australian Occupational Therapy Journal, 54, 88-94.

Dahmann, N., Wolch, J., Joassart-Marcelli, P., Reynolds, K., \& Jerrett, M. (2010). The active city? Disparities in provision of urban public recreation sources. Health and Place, 16, 431-445.

Davison, K.K., \& Birch, L.L. (2001). Childhood overweight: A contextual model and recommendations for future research. Obesity Review, 2(3), 159-171.

Floyd, M.F., Spengler, J.O., Maddock, J., Gobster, P.H., \& Suau, L. (2008). Park-based physical activity in diverse communities of two U.S. cities: An observational study. American Journal of Preventive Medicine, 34, 299-305. 
Floyd, M.F., Taylor, W.C., \& Whitt-Glover, M.C. (2009). Measuring park and recreation environments in low-income communities of color: Highlights of challenges and recommendations. American Journal of Preventive Medicine, 36 (S1), S156-S160.

Gomez, J.E., Johnson, B.A., Selva, M., \& Sallis, J.F. (2004). Violent crime and outdoor physical activity among inner-city youth. Preventive Medicine, 39(5), 876-881.

Gordon-Larsen, P., McMurray, R.G., \& Popkin, B.M.. (2000). Determinants of adolescent physical activity and inactivity patterns. Pediatrics, 105(6), E83.

Gordon-Larsen, P., Nelson, M.C., Page, P., \& Popkin, B.M. (2006). Inequality in the built environment underlies key health disparities in physical activity and obesity. Pediatrics, 117, 417-24.

Grow, H.M., Saelens, B.E., Kerr, J., Durant, N.H., Norman, G.J., \& Sallis, J.F. (2008). Where are youth active? Roles of proximity, active transport, and built environment. Medicine \& Science in Sports \& Exercise, 40(12), 2071-2079.

Humbert, M.L., Chad, K.E., Spink, K.S., Muhajarine, N., Anderson, K.D., Bruner, M.W., Girolami, T.M., Odnokon, P., Gryba, C.R. (2006). Factors that influence physical activity participation among high- and low-SES youth. Qualitative Health Research, 16, 467-483 
Institute of Medicine (2005). Preventing Childhood Obesity: Health in the Balance. Koplan, J. P., Liverman, C.T., Kraak, V.I. (eds). The National Academies Press, Washington D.C., pp. 8384.

Krueger, R. A. \& Casey, M.A. (2000). Focus Groups: A Practical Guide for Applied Research. 3rd Edition. Thousand Oaks, CA: Sage Publications.

Kumanyika, S.K. \& Grier, S. (2006). Targeting interventions for ethnic minority and low-income populations. The Future of Children, 6(1), 187-207.

Lane, J. \& Meeker, J.W. (2005). Theories and fear of gang crime among Whites and Latinos: A replication and extension of prior research. Journal of Criminal Justice, 33(6), 627-641.

Lane, J. \& Meeker, J.W. (2003). Fear of gang crime: A look at three theoretical models. Law \& Society Review, 37(2), 425-456.

Loukaitou-Sideris, A. (2002). Children in Los Angeles parks: a study of equity, quality and children's satisfaction with neighborhood parks. Town Planning Review, 73, 467-488.

Miech, R.A., Kumanyika, S.L., Stettler, N., et al. (2006). Trends in the Association of Poverty with Overweight among US Adolescents, 1971-2004. JAMA, 295, 2385-2393. 
Miles, R. (2008). Neighborhood disorder, perceived safety, and readiness to encourage use of local playgrounds. American Journal of Preventive Medicine, 34, 275-281.

Moore, B.J., Glick, N., Romanowski, B., \& Quinley, H. (1996). Neighborhood safety, child care, and high costs of fruit and vegetables as barriers to increased activity and healthy eating and linked to overweight and income. FASEB Journal, 10, A562.

Morgan, D. L., \& Krueger, R. A. (1998). The Focus Group Kit, Volumes 1-3, Sage Publications, Thousand Oaks, CA.

Mota, J., Almeida, M., Santos, P., \& Ribeiro, J.C. (2005): Perceived neighborhood environments and physical activity in adolescents. Preventive Medicine, 41(5-6), 834-836.

Naylor, P.J. \& McKay, H.A. (2009). Prevention in the first place: Schools a setting for action on physical inactivity. British Journal of Sports Medicine, 43, 10-13.

Norman, G.J., Nutter, S.K., Ryan, S., Sallis, J.F., Calfas, K.J., \& Patrick, K. (2006). Community design and access to recreational facilities as correlates of adolescent physical activity and BodyMass Index. Journal of Physical Activity and Health, 3 (S1), S118-S128.

Ogden, C.L., Carroll, M.D., Kit, B.K., \& Flegal, K.M. (2012). Prevalence of obesity and trends in body mass index among US children and adolescents, 1999-2010. JAMA, 307(5), 483-490. 
Powell, L.M., Chaloupka F,J,, Slater, S.J., Johnston, L.D., \& O’Malley, P.O. (2007). The availability of local area commercial physical activity-related facilities and physical activity among adolescents. American Journal of Preventive Medicine, 33(4S), S292-S300.

Powell, L.M., Slater, S.J., Chaloupka, F.J., \& Harper, D. (2007). Availability of physical activity-related facilities and neighborhood demographic and socioeconomic characteristics: a national study. American Journal of Public Health, 96(9), 1676-1680.

Powell, L.M., Slater, S.J., Chaloupka, F.J., \& Harper, D. (2006). Availability of physical activity-related facilities and neighborhood demographic and socioeconomic characteristics: A national study. American Journal of Public Health, 96, 1676-1680.

Powell, L.M., Slater, S.J., \& Chaloupka, F.J. (2004). The relationship between community physical activity settings and Race, ethnicity, andsocioeconomic status. Evidence-Based Preventive Medicine, 1(2), 135-144.

Ries, A.V., Gittelson, J., Voorhees, C.C., Roche, K.M., Clifton, K.J., \& Astone, N.M. (2008). The environment and urban adolescents' use of recreational facilities for physical activity: A qualitative study. American Journal of Health Promotion, 23, 43-50.

Sallis, J.F., Cervero, R., Ascher, W.W., Henderson, K., Kraft, M., \& Kerr, J. (2006). An ecological approach to creating active living communities. Annual Review of Public Health, 27, 14.1-14.26. 
Sallis, J.F., Nader, P.R., Broyles, S.L., \& Berry, C.C. (1993). Correlates of physical activity at home in Mexican-American and Anglo-American preschool children. Health Psychology,12(5), 390-398.

Singer, E. \&Kulka, R.A.(2002). Paying respondents for survey participation. In: VerPloeg M, Moffitt RA, Citro CF, eds. Studies of welfare populations: data collection and research issues. Washington DC: National Academy Press, 105-22.

Shores, K.A, \& West, S.T. (2008). The relationship between built park environments and physical activity in four park locations. Journal of Public Health Management and Practice, 14(3), E9-E16.

Slater, S.J., Ewing, R., Powell, L., Chaloupka, F., Johnston, L., \& O’Malley, P. (2010). The association between community physical activity settings and youth physical activity, overweight and BMI. Journal of Adolescent Health, 47(5), 496-503.

Stodolska, M., Acevedo, J.C., \& Shinew, K.J. (2009). Gangs of Chicago: Perceptions of crime and its effects on the recreation of Latino residents in urban communities. Leisure Sciences, 31(5), 466-482.). 
Taylor, W., Floyd, M.F., Whitt-Glover, M., \& Brooks, J. (2007). Environmental justice: A framework for collaboration between the public health and recreation and parks fields to study disparities and physical activity. Journal of Physical Activity and Health, 4(1), S20-S29.

Tester, J. \&Baker, R. (2009). Making the playing fields even: Evaluating the impact of an environmental intervention on park use and physical activity. Preventive Medicine, 48, 316-320.

Timperio, A., Crawford, D., Telford, A., \& Salmon, J. (2004). Perceptions about the local neighborhood and walking and cycling among children. Preventive Medicine, 38(1), 39-47.

Tucker, P., Gilliland, J., \& Irwin, J.D. (2007). Splash pads, swings and shade: Parents' preferences for neighborhood parks. Canadian Journal of Public Health, 98, 198-202.

U.S. Department of Health and Human Services (2008). Physical Activity Guidelines for Americans. (Washington, D.C.). 
Table 1:

Focus Group Participant Characteristics

\begin{tabular}{|c|c|c|c|}
\hline School & $\mathbf{N}$ & Males & Females \\
\hline Predominantly Black & 16 & 6 & 10 \\
\hline Predominantly Latino & 17 & 8 & 9 \\
\hline Total: & 33 & $14(42 \%)$ & $19(58 \%)$ \\
\hline Breakdown by Grade & $\mathbf{N}$ & Males & Females \\
\hline $6^{\text {th }}$ Graders & 4 & $3(21.5 \%)$ & $1(5 \%)$ \\
\hline $7^{\text {th }}$ Graders & 22 & $8(57 \%)$ & $14(74 \%)$ \\
\hline $8^{\text {th }}$ Graders & 7 & $3(21.5 \%)$ & $4(21 \%)$ \\
\hline
\end{tabular}


Table 2:

Focus Group School and Neighborhood Characteristics

\begin{tabular}{|l|r|r|}
\hline School Characteristics & \multicolumn{1}{l|}{ School A } & \multicolumn{1}{l|}{ School B } \\
\hline School Type & Neighborhood & Neighborhood \\
\hline Total $6^{\text {th }}, 7^{\text {th }}$ and $8^{\text {th }}$ grade students at school & $\sim 150$ & $\sim 300$ \\
\hline Race/Ethnicity & $99.2 \%$ Black & $95.7 \%$ Hispanic \\
\hline Mobility & $29.3 \%$ & $12.0 \%$ \\
\hline$\%$ Low Income Students & $99.8 \%$ & $94.7 \%$ \\
\hline Attendance Rate & $92.7 \%$ & $95.4 \%$ \\
\hline Neighborhood Characteristics & $97.2 \%$ Black & $63.9 \%$ Hispanic \\
\hline Neighborhood Race/Ethnicity & $\$ 29,918$ & $\$ 47,017$ \\
\hline Neighborhood Median Income & 6961 & 2974 \\
\hline Annual Neighborhood Crimes (City Avg. 4926) & 1.9 sq. mi. & 3 sq. mi. \\
\hline Area & 185 acres & 300 acres \\
\hline Largest Neighborhood Park & & \\
\hline
\end{tabular}


Table 3:

Summary of Focus Group Findings

\begin{tabular}{|c|c|c|}
\hline Factor & Males & Females \\
\hline $\begin{array}{l}\text { Average number of } \\
\text { settings visit regularly } \\
\text { (once a week or more) }\end{array}$ & 3 & $2-3$ \\
\hline $\begin{array}{l}\text { Main reason for } \\
\text { frequenting settings }\end{array}$ & $\begin{array}{l}\text {-Convenience/close to home } \\
\text { - To play sports and utilize } \\
\text { features }\end{array}$ & $\begin{array}{l}\text {-Convenience/close to home } \\
\text {-To socialize with friends }\end{array}$ \\
\hline $\begin{array}{l}\text { Barriers to Exercise } \\
\text { (excluding general safety } \\
\text { issues) }\end{array}$ & $\begin{array}{l}\text {-None, males said they exercise } \\
\text { wherever and whenever they } \\
\text { can regardless of the condition } \\
\text { of the features }\end{array}$ & $\begin{array}{l}\text {-Homework } \\
\text {-Household chores }\end{array}$ \\
\hline $\begin{array}{l}\text { Environmental } \\
\text { knowledge }\end{array}$ & $\begin{array}{l}\text {-Aware of presence of features } \\
\text {-Aware of programs offered } \\
\text {-Aware of PA setting Hours of } \\
\text { Operation } \\
\text {-Aware of Age Restrictions for } \\
\text { Specific features (e.g., exercise } \\
\text { equipment) } \\
\text {-Aware of condition of features } \\
\text {-Aware of facility use and } \\
\text { program costs, but not specific } \\
\$ \text { amounts }\end{array}$ & $\begin{array}{l}\text {-Less aware of presence of } \\
\text { features } \\
\text {-Less aware of programs } \\
\text { offered } \\
\text {-General awareness of } \\
\text { condition of settings } \\
\text {-Aware of facility use and } \\
\text { program cost, but not } \\
\text { specific } \$ \text { amounts }\end{array}$ \\
\hline $\begin{array}{l}\text { Use of Alternative } \\
\text { Settings }\end{array}$ & $\begin{array}{l}\text {-More likely to use other } \\
\text { settings, such as parking lots, } \\
\text { vacant lots, streets }\end{array}$ & $\begin{array}{l}\text {-Did not utilize alternative } \\
\text { settings }\end{array}$ \\
\hline Safety Issues & $\begin{array}{l}\text {-presence of gang members and } \\
\text { other bad people } \\
\text {-familiar with strategies to } \\
\text { avoid unsafe conditions } \\
\text {-parent concerns regarding } \\
\text { safety }\end{array}$ & $\begin{array}{l}\text {-presence of gang members } \\
\text { and other bad people } \\
\text {-parental concerns regarding } \\
\text { safety } \\
\text {-familiar with strategies to } \\
\text { avoid } \\
\text {-familiar with strategies to } \\
\text { avoid unsafe conditions }\end{array}$ \\
\hline
\end{tabular}

